NBER WORKING PAPER SERIES

\title{
THE PERSISTENCE OF EMERGING \\ MARKET EQUITY FLOWS
}

\author{
Jessica Tjornhom Donohue \\ Kenneth A. Froot
}

Working Paper 9241

http://www.nber.org/papers/w9241

\author{
NATIONAL BUREAU OF ECONOMIC RESEARCH \\ 1050 Massachusetts Avenue \\ Cambridge, MA 02138 \\ October 2002
}

We are grateful to State Street Corporation for help in obtaining data and to Gang Bai for extraordinarily effective research assistance. The views expressed here are ours, and we alone bear responsibility for any mistakes or inaccuracies. The views expressed herein are those of the authors and not necessarily those of the National Bureau of Economic Research.

(C) 2002 by Jessica Tjornhom Donohue and Kenneth A. Froot. All rights reserved. Short sections of text, not to exceed two paragraphs, may be quoted without explicit permission provided that full credit, including (C) notice, is given to the source. 
The Persistence of Emerging Market Equity Flows

Jessica Tjornhom Donohue and Kenneth A. Froot

NBER Working Paper No. 9241

October 2002

JEL No. G15, F21, G11

\section{$\underline{\text { ABSTRACT }}$}

The portfolio flows of institutional investors have been found to be highly persistent across countries and individual investment funds. This paper investigates the source of this persistence in emerging market equities. We employ the decomposition methodology of Froot and Tjornhom (2002), which decomposes the persistence of flows into four components: (i) own-country, own-fund persistence (which might arise from informed trading within each country by individual funds); (ii) own-country, cross-fund persistence (which might arise from asynchronicities across funds); (iii) cross-country, own-fund persistence (which might arise from asynchonicities within a fund) and (iv) cross-country, cross-fund persistence (which might arise from other reaction lags - such as contagion - across both countries and funds). We find evidence that all four components are positive in emerging markets. Our results differ from those in developed countries, in that we attribute approximately 10\%-20\% of total persistence to cross-country effects (iii) and (iv). These findings are consistent with stories of contagion, which suggest that demand shifts move predictably from one country to another. They cannot easily be explained by informed trading alone or by wealth effects.

Jessica Tjornhom Donohue

State Street Associates

138 Mt. Auburn Street

Cambridge, MA 02138

jtdonohue@statestreet.com
Kenneth A. Froot

Graduate School of Business

Harvard University

Soldiers Field

Boston, MA 02163

and NBER

kfroot@hbs.edu 


\section{Introduction}

In a number of studies, the portfolio flows of institutional investors have been shown to be persistent. ${ }^{1}$ Inflows into a particular region at one date predict positively further inflows into that same region on future dates. This appears to hold at daily, weekly, monthly, and even quarterly horizons. The persistence is quite high, with first-order autocorrelation coefficients often in the range of $30 \%-35 \%{ }^{2}$

Persistence in net purchases by institutional investors seems important given the relationship institutional flows appear to have with market prices. Current returns are strongly positively correlated with current institutional flows and current institutional flows tend to react positively to past returns. In addition, there is some evidence that current flows are positively predictive of future returns. These associations suggest that institutional flows may be bound up with return momentum in equities, and may help separate out and identify different sources of momentum. ${ }^{3}$

Typically, however, flow data are aggregated across investors, and often, across countries as well. Consequently, the observed persistence may come simply from persistent flows investor by investor. But it could also come from cross-investor investment lags, from lags across countries by individual investors, or from lags across both investors and countries. These different sources of persistence represent very different driving mechanisms. This paper follows Froot and Tjornhom (2002) in decomposing aggregate flow persistence into constituent components so as to determine which of these mechanisms is most important. Froot and Tjornhom (2002) focuses on developed country equities, whereas the present paper focuses on emerging market equities.

\footnotetext{
${ }^{1}$ Choe, Kho, and Stulz (1999, 2001), Kim and Wei (2001), and Seasholes (2001) provide evidence on the persistence of Asian equity flows by foreigners (who are mostly institutions). Richards (2002), Froot, O'Connell, and Seasholes (2001), Froot and Ramadorai (2002) and Kaminsky, Lyons, and Schmukler (2000), provide evidence of the persistence of cross-border institutional investor flows, both in equities and foreign exchange.

${ }^{2}$ See Froot, O'Connell, and Seasholes (2001).

${ }^{3}$ A number of papers study the relationship between institutional flows and equity returns both in the US and internationally. See Cohen, Gompers, and Vuolteenaho (2001), Froot, O'Connell, and Seasholes (2001), Froot and Ramadorai (2001), Grinblatt and Keloharju, (2000), Grinblatt, Titman, and Wermers (1995), Lakonishok, Shleifer, and Vishny (1992), Nofsinger and Sias (1999), Richards (2002), Wermers $(1999,2000)$.
} 
What are the main components of aggregate flow persistence? First, and most important is what we call own-fund, own-country persistence. This source of persistence arises in models of informed trading (e.g., Kyle 1985), where informed order flow is derived to be conditionally autocorrelated. The autocorrelation occurs because traders with positive information attempt to disguise it, rationing their purchases at any given time and deferring some into the future, in order to 'hide' among other sources of order flow, and thereby reduce total price impact. Of course, the 'informed' trader need not have information that is correct. All that matters is that information is perceived. If the source of information is pure perception only, then there is trader overconfidence. But order flow remains conditionally autocorrelated nevertheless.

We call this source of persistence the informed-trading hypothesis following Froot and Tjornhom (2002). In the present context, it predicts that each fund's purchases of a given country's equities are likely to be own-autocorrelated. The autocorrelation emerges because individual fund managers have either company-specific or country-specific information (real or perceived) and dispense it slowly and optimally into prices.

The informed trading hypothesis also has cross-fund and cross-country implications. Suppose for example that two separate investment funds learn something about the same country at the same time. Each will spread over time their trades in a way that is optimal, leading to own-fund, owncountry persistence. However, if the econometrician is to look for cross-fund, own-country persistence, she will find it, at least insofar as there is positive non-contemporaneous correlation between one fund's flows and another's. However, after accounting for the own-fund, owncountry persistence, this cross-fund, own-country persistence will disappear. The same is true for components of aggregate persistence (other than own-fund, own-country persistence) as well. Consequently, it is important to control for the expected impact of the informed trading hypothesis across all the components of aggregate persistence.

The second main component of aggregate flow persistence is cross-fund, own-country persistence. After controlling for own-fund, own-country persistence, what might explain this component? The most general alternative explanation for cross-fund, own-country persistence is a lack of simultaneity. This may arise from many different sources. One is that there may be lags associated with investment infrastructure, bureaucracy, or decision-making. For example, investors may process information or come to opinions at different speeds; they may face implementation lags in pulling the trigger. Another is that managers respond positively to each 
other's decisions with some lag. Such responses might be construed as a form of investor herding. However, the cause of the herding could be quite rational. Fund managers might find that they increase returns by following first movers. ${ }^{4}$ Or they might find that following first movers reduces tracking error against a peer benchmark and therefore provides a kind of agencyinduced risk reduction.

The third important component of persistence is own-fund, cross-country persistence. There are several mechanisms that may lay behind such persistence. One is that - once again - there are mechanical leads and lags in investment processes, but here these actually occur across investments within a single fund, rather than across funds. Such within-fund mechanical or implementation lags are harder to envision than their cross-fund analogs. A second is that there is a kind of within-fund contagion effect, whereby flows into or out of one market, result in followon flows into or out of another market. If contagion is the process by which flows move predictably from one country to another, then this would seem to be a within fund behavioral factor. Finally, shocks to fund wealth may result in rebalancing transactions that take time to complete. (Perhaps this is just another form of implementation lag.) A decline in wealth in one country may force rebalancing outflows from a set of other countries where market values did not decline. If there are important leads and lags in these rebalancing transactions would we see wealth-effect-driven persistence (for a model along these lines, see Kyle and Xoing, 2001). The rebalancing story does not require that own-fund, cross-country persistence is positive.

The fourth and final component of persistence is cross-fund, cross-country persistence. Here we see that current outflows from a given country by one fund are positively correlated with future outflows from other countries by other funds. This effect seems unlikely to be driven by mechanical leads and lags, and is most closely associated, it would seem, with contagion.

In terms of our findings, our first set of results is quite similar to those in Froot and Tjornhom (2002). We begin by performing a naïve decomposition of aggregate persistence. It is 'naïve' because we do not control for own-fund, own-country persistence in measuring the components. As expected, we find that own-fund own-country persistence is not very important. Own-fund own-country persistence explains about $7 \%$ of total persistence, with the rest coming from cross effects. This is not very surprising given the sheer size of our cross section (471 funds $\mathrm{x} 15$

\footnotetext{
${ }^{4}$ See Froot, Scharfstein, and Stein (1992) for a model in which it is rational on the basis of expected returns to follow others.
} 
countries). Most important would appear to be the cross-fund components, which is predominantly because the number of funds is large compared to the number of countries.

As in Froot and Tjornhom (2002), we find a very different picture when we condition on the size of the own-fund own-country persistence. We ask whether the cross components are large given the magnitude of observed own-fund own-country persistence. The answer for all three other components is 'yes': both cross-country and cross-fund components are larger than we would expect them to be under the informed trading hypothesis. In other words, as in Froot and Tjornhom, there is 'excess' persistence in the data. Indeed, we find that this excess persistence accounts for about one-third of the total. While there is evidence that the informed trading hypothesis is operative, we reject the null in which informed trading is a complete explanation of persistence. We do so in favor of an alternative that there is a slow rippling of flow across funds for a given country, across countries within a given fund, or across both funds and countries.

It is at this point that we find important differences for emerging markets versus the Froot and Tjornhom (2002) benchmark for developed markets. In emerging markets there is strong evidence that every one of the components contributes positively to overall persistence. This is in stark contrast with the developed country results where only cross-fund, own-country persistence is positive. The additional cross-country components - both own- and cross-fund - appear to matter only in emerging markets.

What might account for our findings of additional cross-country persistence in emerging markets? Two stories strike us as quite plausible. The first is that our specification of the informed-trading null may not be exactly right, so that there is leakage across sources of cross-country persistence. For example, suppose a negative information shock hits two countries at the same time. This generates current and future outflows in each country, which we suppose are driven exclusively by the trading considerations in each country. The informed-trading hypothesis holds, but it still may help to condition future own-country flows on flows into other countries. This would be the case if there are left-out state variables relevant for own-country trading that are correlated with trading in other countries. This could be a greater problem in emerging markets where fluctuations in liquidity may have more important common cross-country factors.

The second story is that funds show greater 'contagion' like responses across countries, so that outflows from one country affect outflows from another country with a lag. When bad news hits 
a given country, sales may commence immediately. Sales in other countries - even within the same fund - commence only with a lag. This happens for emerging markets but not for developed. It seems implausible that a given fund cannot begin selling in multiple countries simultaneously. Managers may therefore only become concerned later about impacts across other countries, creating lags in commencing those sales. This explanation is likely to be behavioral, not rational, because it appears that funds could have correctly forecasted that they would soon be selling in other countries with a lag. This story works across funds somewhat better: after one fund's active reaction to new information in a given country, another fund may deliberately follow, beginning to sell in the original country, as well as other countries. Perhaps one fund is trying to earn a return by free-riding off another's decisions with a lag. Or perhaps the second fund sees the first's decision as a change in its peer-driven benchmark. Either way, cross-country persistence is evident in the emerging market flows.

Empirically, our findings appear quite robust. With nearly 9 million fund/country/day flow data points, statistical power is not really an issue; all of the above rejections of the null are highly statistically significant, while the failures to reject reflect extremely (economically) small point estimates. Second, the results are essentially unchanged whether persistence is measured in daily or weekly data. In fact, the results are somewhat stronger in weekly flow data, suggesting that some of these patterns may occur at even lower frequencies than we estimate here. Third, there is only a small difference in the estimates of own-country effects for developed versus emerging markets: emerging markets feature slightly higher levels of persistence, are quite similar nevertheless.

The rest of the paper is structured as follows. Section II discusses the decomposition. Section III describes the data. Section IV provides some basic descriptive statistics. Section V discusses the main results and Section VI concludes.

\section{Decomposition ${ }^{5}$}

Let us begin with the established fact (which we also confirm below in our data): that institutional order flow aggregated across funds and countries is autocorrelated:

\footnotetext{
${ }^{5}$ This section follows the decomposition of Froot and Tjornhom (2002) closely.
} 


$$
f_{t}=\delta+\alpha f_{t-\tau}+\varepsilon_{t}
$$

where flow is aggregated across funds $(i=1, \ldots, I)$ and countries $(k=1, \ldots K), f_{t}=\sum_{i} \sum_{k} f_{i, k, t}$. With respect to normalization of the flows, there is no clearly dominant solution.

One approach, used commonly, is to normalize the underlying value of flow by country market capitalization as a way of controlling for differences in market capacity, i.e., $f_{i, k, t}=\frac{F_{i, k, t}}{M_{k, t-1}}$, where $F_{i, k, t}$ is the dollar amount of net flow into country $k$ by fund $i$, summed across all transactions on date $t$, and $M_{k, t}$ is the dollar market capitalization of the $k$ th country.

Clearly, this normalization does not condition on fund size at all. This is typical in that previous papers have simply used aggregated dollar amounts across managers. However, with our disaggregated data, we have the flexibility to weight flow differently. One simple approach that puts different markets and funds on a more similar footing is a digital normalization. It treats all fund/countries with net buys (sells) on a given day as having the same as the same flow magnitude, i.e., $f_{i, k, t}^{d}=\operatorname{sign}\left(\frac{F_{i, k, t}}{M_{k, t-1}}\right)$, where $\operatorname{sign}($.) returns either 1,0 , or -1 .

A second approach to normalization uses the net buy count for each fund/country/date. Letting $B_{i, k, t}$ and $S_{i, k, t}$ represent the number of buys and sell, respectively for each fund/country/date, we define a flow count normalization to be $f_{i, k, t}^{c}=\frac{B_{i, k, t}-S_{i, k, t}}{B_{i, k, t}+S_{i, k, t}}$.

In what follows, we rely on $f_{i, k, t}^{c}$, since it is guaranteed to be comparably scaled across both funds and countries.

Once we have chosen the normalization, we need to characterize the sources of persistence. This becomes a four-dimensional problem if we want to characterize generally the noncontemporaneous cross-correlation between $f_{i, k, t}$ and $f_{j, l, t-\tau}$. To be specific, the $\tau$ th-order 
normalized cross covariance is given by $\rho_{i, k, j, l}^{\tau}=\frac{\operatorname{cov}\left(f_{i, k, t}, f_{j, l, t-\tau}\right)}{\operatorname{var}\left(f_{t}\right)}$, and the corresponding covariance matrix by $\Gamma(1)$. The $\tau$ th-order autoregressive coefficient of total flow above, $\alpha(\tau)$, is given by: ${ }^{6}$

$$
\alpha(\tau)=\sum_{i} \sum_{j} \sum_{k} \sum_{l} \frac{\operatorname{cov}\left(f_{i, k, t}, f_{j, l, t-\tau}\right)}{\operatorname{var}\left(f_{t}\right)}
$$

In order to make some headway in reducing the dimensionality of the problem, we divide up these terms. We can afford to do this: since we employ data on 471 funds and 15 countries, $\Gamma(\tau)$ has about 50 million elements for a single lag, $\tau$.

We therefore divide things using the simple distinction between own versus cross correlations in each dimension. This brings us down to just 4 components, two in each dimension. Specifically, we group the $\Gamma(\tau)$ matrix as (this is depicted visually in Figure 1 below):

$$
\begin{aligned}
\alpha(\tau)= & \sum_{k} \sum_{i}\left(\frac{\operatorname{cov}\left(f_{i, k, t}, f_{i, k, t-\tau}\right)}{\operatorname{var}\left(f_{t}\right)}+\sum_{j \neq i} \frac{\operatorname{cov}\left(f_{i, k, t}, f_{j, k, t-\tau}\right)}{\operatorname{var}\left(f_{t}\right)}\right. \\
& \left.+\sum_{l \neq k} \frac{\operatorname{cov}\left(f_{i, k, t}, f_{i, l, t-\tau}\right)}{\operatorname{var}\left(f_{t}\right)}+\sum_{j \neq i} \sum_{l \neq k} \frac{\operatorname{cov}\left(f_{i, k, t}, f_{j, l, t-\tau}\right)}{\operatorname{var}\left(f_{t}\right)}\right)
\end{aligned}
$$

To save space, assume that each of the covariances above is constant, so that we can estimate a single parameter for each. That is, we impose the following restrictions, each corresponding to a specific type of covariation.

1. Equal Own-fund own-country covariations:

$$
\frac{\operatorname{cov}\left(f_{i, k, t}, f_{i, k, t-\tau}\right)}{\operatorname{var}\left(f_{t}\right)}=\alpha_{\mathrm{oo}}(\tau) \text { for all } i, k \text { pairs. }
$$

This can be seen in Figure 1 as the main diagonal of the covariance matrix. Own-fund, owncountry persistence is probably easiest to interpret. It comes from persistence in each fund's

\footnotetext{
${ }^{6}$ Partial $\tau^{\text {th }}$-order coefficients use only the portion of $f_{i, k, t}$ that is orthogonal to the prior $\tau-1$ lags.
} 
purchases of a country's equities. For example, Hong Kong equity inflows may be persistent because a given fund's purchases of Hong Kong equities today will on average continue for several days. Own-fund own-country persistence is what we would expect from an informed investor in the Kyle (1985) model. It is also what we would expect from an overconfident investor who behaves as though he has information. ${ }^{7}$

2. Equal cross-fund own-country covariations:

$$
\sum_{j \neq i} \frac{\operatorname{cov}\left(f_{i, k, t}, f_{j, k, t-\tau}\right)}{\operatorname{var}\left(f_{t}\right)}=\alpha_{\mathrm{co}}(\tau) \text { for all } i \neq j, \text { and for all } k
$$

This source of persistence can be seen as the triangles along the main diagonal of Figure 1. This component is driven by non-synchronized purchases across funds of the same country's equities. For example, suppose a given fund buys Hong Kong equities today. While that fund may not on average purchase more Hong Kong equities tomorrow (i.e., $\left.\alpha_{\mathrm{oo}}(\tau)=0\right)$, other funds may tend to purchase Hong Kong equities at that time. The information or opinion that causes one fund to trade Hong Kong equities may ripple out across funds over time, creating persistence in Hong Kong flows. We call this cross-fund own-country persistence.

This source of cross-persistence is analogous in many ways with the source of cross-persistence that has been observed in equity index returns. Of course, cross-fund persistence is likely to be far richer than own-fund persistence, especially when there is a relatively large cross section of funds. To continue the analogy with stock returns, cross-persistence arises partly from returns on large firms predicting returns on small firms. This effect becomes more intensive within a given industry. Similar patterns are likely to be operative across funds. As groups, passive index funds versus active funds are not likely to demonstrate much cross-fund persistence. Such crosspersistence is likely to be much more important within each group of funds rather than across the groups.

As a first step, we impose the restriction in 2 above, estimating the average off-diagonal covariance.

\footnotetext{
${ }^{7}$ We do not test in this paper the information content of institutional investor trades, so we are agnostic here about whether persistent trades are the result of information or overconfidence.
} 


\section{Equal own-fund cross-country covariations}

$$
\sum_{l \neq k} \frac{\operatorname{cov}\left(f_{i, k, t}, f_{i, l, t-\tau}\right)}{\operatorname{var}\left(f_{t}\right)}=\alpha_{\mathrm{oc}}(\tau) \text { for all } k \neq l, \text { and for all } i
$$

Figure 1 shows own-fund cross-country covariances as the minor diagonal lines. Flows into a given country from a given fund may be correlated with past flows into other countries from the same fund. A fund buying Hong Kong equities today might buy Australian equities tomorrow. Reasons for this source of persistence include a substitution effect towards Australian equities as Hong Kong equity prices rise, an implementation lag in getting to Australian equities, an emerging appreciation that the news for Japan also may apply to Australia, etc. In addition, ownfund cross-country covariation may occur in the context of strong own-fund own-country correlation. If purchases of both Hong Kong and Australian equities show strong own persistence, then purchases of both markets initiated at similar times will also generate own-fund, crosscountry covariation.

\section{Equal cross-fund cross-country covariations}

$$
\sum_{j \neq i} \sum_{l \neq k} \frac{\operatorname{cov}\left(f_{i, k, t}, f_{j, l, t-\tau}\right)}{\operatorname{var}\left(f_{t}\right)}=\alpha_{\mathrm{cc}}(\tau) \text { for all } i \neq j \text {, and } k \neq l \text {. }
$$

Figure 1 shows cross-fund cross-country covariances as the triangles surrounding the minor offdiagonal lines. This is the most dispersed form of persistence. Purchases of a given country by one fund may over time diffuse toward purchases by other funds of other countries.

Together, these four restrictions can be used to decompose the aggregate autocorrelation of total flows, shown in equations (1) and (2):

$$
\alpha(\tau)=I K\left(\alpha_{o o}(\tau)+\alpha_{c o}(\tau)+\alpha_{o c}(\tau)+\alpha_{c c}(\tau)\right)
$$

These four components of $\alpha$ can be estimated using OLS in the individual regressions

$$
f_{i, k, t}=c+a(L) x+\varepsilon_{t}
$$


where $a(L)$ takes on the values, $\alpha_{o o}(\tau), \alpha_{o c}(\tau), \alpha_{c o}(\tau)$, and $\alpha_{c c}(\tau)$, when $x$ takes on the values

$$
\begin{gathered}
c_{o o} f_{j, k, t-\tau}, \\
c_{o c} \sum_{j \neq i} f_{j, k, t-\tau}, \\
c_{c o} \sum_{l \neq k} f_{i, l, t-\tau}, \\
\text { and } c_{c c} \sum_{j \neq i} \sum_{l \neq k} f_{j, l, t-\tau},
\end{gathered}
$$

respectively, and where the $c$ 's are constants of proportionality such that in all four cases the standard deviation of $x$ equals that of aggregate flow, $f_{t}$.

\section{II.A. Is flow persistence driven entirely by informed trading?}

This decomposition provides perspective on the magnitude of the individual own- and crosseffects driving aggregate flow persistence. We need to go an additional step, however. The informed/overconfident trader hypothesis that we discuss above suggests that own-purchases are serially correlated. Traders get slowly into positions and the magnitude of their trades is a function to the perceived difference between value and price. In the continuous auction environment of Kyle (1985), market depth (i.e., the sensitivity of price to incremental order flow) is constant. In expectation, as the informed trader pushes price towards perceived value, trade size declines. In this sense flow is stationary and persistent with respect to shocks to perceived value.

If we take the informed trader story as our null hypothesis, we would predict that cross-country and cross-fund persistence emerge as a result. These additional sources of persistence emerge because perceived opportunities may be contemporaneously correlated across countries. In the presence of own-fund own-country persistence, contemporaneous correlation across funds and countries will translate into non-contemporaneous correlation.

To see this, take the simple case in which flows for a given fund / country are autoregressive and stationary, and have iid news (or overconfidence) shocks: 


$$
f_{i, k, t}=\theta_{i, k}(L) f_{i, k, t-1}+\xi_{i, k, t}
$$

where $L$ is the lag operator. Given stationarity, it follows that $f_{i, k, t}$ can be written as a moving average process, $f_{i, k, t}=\phi_{i, k}(L) \xi_{i, k, t}$, where $\phi_{i, k}(L)=\left(1-\theta_{i, k}(L)\right)^{-1}$. Even though the $\xi$ shocks are serially uncorrelated across all funds and countries ( $i$ and $k$ ), they may be contemporaneously correlated across both funds and countries. As a result, even small amounts of contemporaneous correlation between $\xi_{i, k, t}$ and $\xi_{j, l, t}$ can generate important non-contemporaneous cross-country and/or cross-fund correlations between $f_{i, k, t}$ and $f_{j, l, t-\tau}$ under the informed/overconfident trader hypothesis.

Notice, however, that if we can control properly for the own-autoregressive correlations in $f_{i, k, t}$, then the remaining own-flow components will be uncorrelated across funds, countries, and time. That is, after controlling for the own-autoregressive part of $f_{i, k, t}$, we are left with $\xi_{i, k, t}$. These own-flow innovations are uncorrelated with past own- and cross-flow innovations. That is, $\xi_{i, k, t}$ is uncorrelated with $\xi_{j, l, t-\tau}$, for all values of $i, j, k, l$, and $\tau>0$.

Consider, then the regression:

$$
f_{i, k, t}=c+a_{o o}(L) f_{i, k, t-1}+\frac{a_{c o}(L)}{I-1} \sum_{j \neq i} f_{j, k, t-1}+\frac{a_{o c}(L)}{K-1} \sum_{l \neq k} f_{i, l, t-1}+\frac{a_{c c}(L)}{(I-1)(K-1)} \sum_{j \neq i} \sum_{l \neq k} f_{j, l, t-1}+\varepsilon_{i, k, t}
$$

where we have made the coefficients easier to compare with one another by dividing by the number of funds and countries over which we sum (i.e., by $(I-1)$ and $(K-1)$, respectively). This specification sops up the own-flow own-country persistence and tells us the size and significance of average measures of cross flows. Thus, the informed trader hypothesis suggests that the ownfund own-country coefficient is positive, $a_{o o}(L)>0$, and that the cross coefficients are zero, $a_{c o}(L)=a_{o c}(L)=a_{c c}(L)=0$. Our alternative hypotheses are that one or more of these latter coefficients are different from zero. These coefficients represent the extent to which there is excess covariation in flows across funds and countries. Essentially, if these latter coefficients are 
different from zero, then there must be some other source of flow correlation beyond the attempt to hide perceived information from the market.

For example, suppose that $a_{c o}(L)>0$, so there is excess cross-fund, own-country persistence. This suggests that some funds react to the same news as other funds with a lag in terms of investing in country $k$. As mentioned above, this lag may be driven by predictable implementation and decision-making lags and delays.

Alternatively, suppose that $a_{o c}(L)>0$, which corresponds to excess own-fund, cross-country persistence. This suggests that there are delayed reactions across country investments within a fund. Here, peer and herding explanations of the lags are not appropriate. The only sensible source would seem to be implementation lags and delays and a behavioral within-fund contagion effect.

Finally, consider the possibility that $a_{c c}(L)>0$, so that there is excess cross-fund, cross-country persistence. Here the same implementation lags are a possible underlying cause, though here they are cross-fund and cross-country (e.g., fund 2 investing in Argentina with a lag behind fund 1's investment in Brazil). Peer and herding issues may also be important here to the extent they span investment opportunities that cannot be categorized neatly by countries. For example, suppose that funds focus on diversifying across corporate sectors, rather than countries. Then cross-fund delays in investing (due to either implementation issues or peer concerns) would necessarily show up as cross-country delays as well. ${ }^{8}$

Note that the specification in equation (6) may be overly restrictive in several ways. First, it assumes own-fund own-country persistence profiles are the same across all countries. This may not be the case. For example, in markets with greater amounts of liquidity (i.e., uninformed order flow), the persistence of informed trading may be less, since the price impact of flow in such markets is likely to be lower.

As a result, it may be useful to allow $a_{o o}$ to vary with $k$, in case there are important differences in own-fund, own-country persistence. Thus, we also estimate:

\footnotetext{
${ }^{8}$ There is increasing evidence that sector allocations are as important, or even more important than country allocations for diversifying risk. See, for example, VanRoyen and Page (2002).
} 
$f_{i, k, t}=c+a_{o o: k}(L) f_{i, k, t-1}+\frac{a_{c o}(L)}{I-1} \sum_{j \neq i} f_{j, k, t-1}+\frac{a_{o c}(L)}{K-1} \sum_{l \neq k} f_{i, l, t-1}+\frac{a_{c c}(L)}{(I-1)(K-1)} \sum_{j \neq i} \sum_{l \neq k} f_{j, l, t-1}+\varepsilon_{i, k, t}$

which is the same specification, except that it also includes separate own-fund own-country autoregressive coefficients for each market, $k, a_{o o ; k}$.

Second, to keep things simple, we have so far restricted the impact of past returns to be zero. It may make sense to measure flow persistence over and above any tendency for flows to chase past returns. This is an approach a number of authors have taken, and, indeed, past returns seem to be statistically significant (though not economically large) in explaining flows. In addition, under our informed trader null hypothesis, past own-country returns should be positively correlated with informed flows. We add both own-country returns and US returns, as there is considerable evidence in Richards (2002) that US returns positively forecast foreign country inflows. ${ }^{9}$

\section{Data}

The flow data used in our analysis are derived from proprietary data provided by State Street Corporation. State Street is one of the world's largest global custodians, with approximately $\$ 7$ trillion of assets under custody. We extract data for a set of 930 distinct funds (without names or identifying characteristics to protect anonymity) from a total of almost 10,000 funds, using the criteria that a fund must trade equities incorporated in 21 or more distinct countries. Because our focus is on active, not passive funds, we reduce the set of funds by choosing only those that, when they are active in the dataset, trade at least $75 \%$ of the days during their active period. We focus on a set of 15 emerging markets leaving us a sample of 471 funds.

Our country designations are somewhat unusual, in that they are driven by an equity issuer's country of incorporation. This definition allows us to include the trading ADRs and GDRs, categorized according to the company's country of incorporation, rather than according to where the security is traded. We focus on the 15 emerging countries based on the number of transactions

\footnotetext{
${ }^{9}$ See papers by Froot, O'Connell, Seasholes (2001), Richards (2002) and Stulz et al and the references therein.
} 
that exist in the reduced dataset. ${ }^{10}$ The set of countries includes Argentina, Chile, Hong Kong, Hungary, India, Indonesia, Israel, Korea, Mexico, Philippines, Poland, Singapore, South Africa, Taiwan, and Thailand. With 2,166 days in the sample since 1994, our ultimate data set has nearly 9 million observations of net flows on a given day, into a given country, by a given fund.

In addition to the flow data, we also employ equity market returns. Returns are calculated using MSCI equity indices for each country used in our sample.

\section{Descriptive Statistics}

In this section we provide some background evidence on how the flow data behave. First, it is useful to get a sense for coverage. Figure 2 depicts the trading by individual funds by sample period dates, where the funds are aligned by first trading date. A date / fund element has no color if there were no trades by that fund on that day across all 15 countries. Note that trades are noticeably less frequent in the early part of the sample. Notice also that there are certain dates during the year when trading is light. The regular vertical lines in the graph correspond to the western Christmas and New Year's holidays.

Figure 3 shows a fund's trades by country as a percentage of the total number of trades by that fund over the period in question. Four periods are given: the entire time series, the intra-crisis period of April 1995 to June 1997, the Asian crisis of July 1997 to September 1998, and the post crisis period of October 1998 to April 2002. Note that the countries are ordered from the highest total number trades across all funds (at the top of each figure to the lowest). It is clear that Hong Kong, Mexico, Korea, and Singapore account for a large percentage of the trading across the entire time period. Several countries have very sparse transactions, including Poland and Hungary, although there are clearly certain funds that concentrate their activities in these countries. ${ }^{11}$ Although we know from Figure 2 that the number of funds in our sample during the intra-crisis period is smaller than any other period we still find some interesting differences. Although Hong Kong and Mexico remain two of the most actively traded countries, Korea and Taiwan are much less actively traded and Indonesia much more relative to other countries. Poland and Hungary remain at the least traded.

\footnotetext{
${ }^{10}$ If there were less than a total of 2,000 transactions for a given country of incorporation using the original set of 930 funds, that country was dropped from our data.
} 
During the crisis period we find that the most actively traded countries were Asian countries with the exception of Mexico, which maintained its position in the ranking, and South Africa, which experienced an increase in activity from the previous period. The only exception was Taiwan. Finally, in the post-crisis period Mexico is replaced by Korea as the second most actively traded country and Taiwan moves from the bottom of the list to near the top. Other Asian countries such as Indonesia, Thailand and the Philippines are traded less actively relative to other countries in the previous periods.

Figure 4 shows net flow volumes instead of number of trades for the same four time periods. Here we see a different ordering of highest to lowest volume countries. When looking at volumes, Hong Kong and Mexico are no longer at the top of the list. Instead we find that flows into Korea are the largest over the entire time series followed by Hong Kong and Taiwan. Mexico becomes the highest flow country during the intra-crisis period replaced by Taiwan and South Africa during the crisis period. Interestingly, during the crisis period Taiwan was actively traded relative to other countries (see Figure 3 ) but the trades that did occur must have been very large to put it on the top of the list for flows. By the final post-crisis period Taiwan and South Africa receive less flows than Korea and Hong Kong. Chile and Argentina are receiving the least flow volume by the post-crisis period even though their relative ranking was higher in each previous time period. Hungary and Poland are near the bottom of the list in all periods except the crisis period where they shoot up to the ranking of three and six respectively. From Figures 4 and 5 it seems there is much more change in relative country rankings when looking at volumes versus number of trades.

Figures 5 and 6 provide heatmaps of contemporaneous correlations of weekly cross-country and cross-regional flows. The country correlations show a very strong positive relationship between Argentina and Chile, Hungary and Poland, and India, Israel and South Africa. However, countries in the East Asian region do not have consistently positive correlations, as Indonesia and the Philippines appear to have a negative correlation with other East Asian countries such as Hong Kong, Korea, and Singapore. In general, countries that are geographically closer seem to have higher correlations, as expected. The weekly correlations in Figure 6 make it clear that there is strong positive correlation in flows across emerging market regions although the Eastern European region is negatively correlated with all other regions.

\footnotetext{
${ }^{11}$ Recall that our country definition of each stock refers to the country of incorporation.
} 
Table 1 reports some descriptive statistics for our net flow measures: dollar flows; digital indicator flows ( 1 for inflow, 0 for no flow, -1 for outflow); and buy-ratio flows (count of buys less sells normalized by buys plus sells). There are several points worth making.

First, the mean net flow by a single fund into a single country on a single day is just over $\$ 2,010$ (Table 1.1). Naturally, because this is a net flow, it is near zero. The daily standard deviation of own-fund own-country flows is much larger, approximately $\$ 299,350$. The mean net inflow while small is nevertheless highly statistically significant. Thus, during our period, there are net mean inflows recorded in our data; domestics on average are selling to international investors around the world.

Second, flows as expected are persistent, as suggested by the partial autocorrelation coefficients in Table 1.2 and 1.3. Both first- and second-order autocorrelations are consistently and statistically positive. For own-fund own-country flows, these autocorrelations are about 39\% $40 \%$ depending on the exact flow measures. This is both economically very large, and, given the large number of data points, is extremely significant (the standard error is much less than $1 \%$ ). It is interesting to note, however, that the own-fund own-country autocorrelations are slightly higher (and statistically so) in the digital and buy/sell count flow indicators than in the raw flows themselves. This is because the scale, but not the direction, of dollar transactions, even for a given fund and given country, jumps around considerably in the data. As a result of these 'outlier' datapoints, digital indicators appear more slightly persistent.

The third point to make is that the persistence is greater for higher levels of aggregation across funds, countries or both. We might expect this because larger aggregations create greater scope for cross-persistence to emerge. For example, for the digital indicator across all countries, the own-fund own-country first-order autocorrelation is $30.7 \%$, own-fund cross-country autocorrelation is $40.2 \%$, cross-fund own-country autocorrelation is $34.6 \%$ and cross-fund crosscountry is $47.1 \% .^{12}$

\footnotetext{
${ }^{12}$ Since we have many more funds than countries in our data, cross-fund own-country aggregations tend to be more highly aggregated than cross-country own-fund aggregations.
} 


\section{Results}

Before interpreting the regressions results, we note that the standard errors are simple OLS. Driving this choice is that we have very many data points, over 9 million, so that many variables appear extremely statistically significant, with t-statistics that range from 10 to 1,000 . Adjustments that are often made to OLS standard errors to account for cross-sectional or autocorrelations of the residuals are unlikely to reverse t-statistics of this magnitude, even in the presence of strong correlations. Indeed, here we have the presence of only weak contemporaneous correlation (see Figures 4 and 5), and, with the use of lagged variables to eliminate autocorrelation, we have very weak serial dependence. As a consequence, OLS standard errors are justified, but still should be interpreted conservatively.

The results of our decomposition of aggregate multi-fund, multi-country flows, $f_{i, k, t}$ are shown in Table 2 . The correlation of aggregate flows is approximately $40 \%$ with a standard deviation of approximately $0.4 \%$. This is about the same level of flow persistence found by Froot, O'Connell and Seasholes (2001) and Richards (2002) for international investors.

Table 2.1 then shows how the 0.40 total breaks down across the four different sources of flow persistence. Much as in the return literature, the vast size of the cross section (both across funds and countries) implies that much of the autocorrelation of total flows is driven by the cross components, rather than own flows. Indeed, Table 2.1 shows that own-fund own-country flows account for only about 0.034 , or about $8.5 \%$ of the overall total 0.40 . Own-fund cross-country flows account for another 0.24 , another $6.0 \%$ or so. So own-fund flows appear relatively unimportant in explaining total flow persistence. While there are more funds than countries, this is nevertheless a relatively small contribution from the own-fund effects.

The large contributions to total flows necessarily come from the two cross-fund components, and do so about equally from cross-fund own-country, and cross-fund cross-country components. These account for 0.181 and 0.161 , respectively, of the total 0.40 . The simple interpretation of this finding would be that the informed trader effects are not very important in explaining flow persistence; we should instead look to lags - particularly across funds and countries - in implementation and decision-making. 
However, this conclusion would be naïve, since some portion of the cross effects might emerge under the informed trading hypothesis. The only way to find out is to examine the multivariate regression results from equation (6).

When we estimate equation (6), we do so in weekly as well as daily data. These results are in Table 3, where there are several things to notice. First, it is clear that own-fund own-country persistence remains very powerful indeed. The first-order correlations generally are in the range of the low 30s (and t-statistics in the hundreds or thousands). The first-order autocorrelation at the daily frequency is $31.1 \%$. Second and third order partial autocorrelations show a similar pattern at $12.3 \%$ and $8.4 \%$, respectively. Under our null hypothesis, own-fund own-country persistence should be directly (negatively) linked to liquidity, and that appears to be the case in the data.

The same estimates for weekly data show a slightly higher first-order autocorrelation, at $36.6 \%$, but lower second and third order correlations $(5.3 \%$ for both the send and third order partial autocorrelations). The weekly estimates are probably somewhat more reliable. Given that the flows happen around the world, their daily timing is harder to pin down. All these numbers continue to be of very high statistical significance.

In terms of the cross effects in Table 3, there are a number of interesting points to notice. First, the most important cross effect is the cross-fund, own-country coefficient. In daily data the firstorder coefficient is approximately $8.5 \%$, with another $1.0 \%$ added by second- and third-order coefficients. In the weekly data, the cross-fund own-country coefficients come in slightly weaker for the first-order partial correlation at $6.4 \%$ but stronger for the second- and third-order coefficients that add $5.7 \%$.

The other cross terms are also positive. The own-fund cross-country coefficients are consistently positive, with the first-order daily coefficient coming in at about $6.5 \%$ (even though the secondorder coefficient is $-1.3 \%$, the third-order coefficient is more than offsetting at $1.8 \%$ ). In the weekly data, the first-order coefficient is again strongly positive, at $4.9 \%$; the second-order coefficient is nearly zero and the third-order is $1.7 \%$. These results suggest that there is a distinctive contribution to aggregate persistence coming from the own-fund cross-country component. 
There is also a positive contribution coming from the cross-fund cross-country persistence term. Here, however, the coefficients are smaller in both daily and weekly data (the first order coefficients average about 2.0\%). Nevertheless, this is measured precisely enough in the daily data to be statistically significant. In the weekly data, the standard errors get to be too large. However, in the weekly data the point estimates of the second and third lags are about the same size as the first lag, contributing cumulatively to a large impact cross-fund, cross-country impact.

Table 4 reports the same set of estimates on lagged flows, but this time including lagged owncountry equity returns (in dollars) as well as US returns. The motivation for including past owncountry returns is considerable previous evidence that institutional equity flows follow momentum strategies (i.e., trend chase), both in US domestic and international flow data. ${ }^{13}$ Most of the research looks at own returns, rather than cross returns. An important exception to this is Richards (2002). He finds that lagged US returns have important positive impacts on international investor flows into Asia stock markets. As a result of this evidence, we try including US returns in addition to local market returns.

The estimates in Table 4 make two important, and striking points. The first is that the lagged flow coefficients are almost completely unchanged with the inclusion of lagged returns. All of the conclusions reached above in the absence of flows remain true when several lags of returns are present. Moreover, the point estimates are very close to being unchanged. Returns may be important, but their absence doesn't cloud any conclusions about flow persistence.

The second point is that lagged own-country equity returns are highly statistically significant, as suggested by the literature on momentum investing. For the 15 emerging countries in our sample, there is no additional explanatory power added through lagged US returns.

Table 5 provides estimates of equation (7). This specification is the same as that in Table 4, except that we allow own-fund own-country persistence to vary by country. This may help account for differences in liquidity across countries. We include lagged returns in Table 5, as well, though, as we just saw, they result in only very minor impacts on lagged flow coefficients.

\footnotetext{
${ }^{13}$ Cohen, Gompers, and Vuolteenaho (2001) find evidence that institutional investors chase only the permanent component of past returns. A temporary positive return is associated with future net sales, not purchases of stocks. Froot and Ramadorai (2001) find a somewhat similar result, that institutional investors' purchases of cross-border stocks follow a measure of permanent return derived from closed-end fund prices.
} 
Because there are now 21 own-fund own-country coefficients (one for each country), we report in the table the average of these coefficients.

The estimates in Table 5 show that many countries have less first-order own-fund own-country persistence than reported for all countries combined. However, the effect appears to be more in the timing rather than in the magnitude of the own-fund own-country autocorrelation. While the first-order own coefficients fall, the second- and third-order coefficients rise by approximately offsetting amounts. The sum of the lagged coefficients in Table 5 (approximately 45\%) remains essentially unchanged from the comparable weekly estimates in Table 4.

\section{Conclusions}

This paper has examined the persistence of institutional investor flows into a set of 15 emerging countries. We confirm previous findings that the portfolio flows of international investors are highly persistent with daily autocorrelations of about $40 \%$. We find that, by a simple additive decomposition, only about $7 \%-8 \%$ of this is attributable to own-fund, own-country components of persistence. Own-fund own-country persistence (which comes only from the trace of noncontemporaneous flow covariance matrix) is relatively unimportant, as might be expected from a large cross section of flow data.

How large should these various own and cross components be relative to one another? To answer this, we refer to what we call the 'informed trader hypothesis,' which says that traders with real or perceived information about a country or a stock, will get into their positions slowly, as long as liquidity is less than perfect. This behavior can explain own- as well as cross-effects and gives us a null hypothesis to determine their relative sizes.

When we implement our test of this, conditioning on the magnitude of own-fund own-country persistence, the nature of the persistence decomposition changes importantly. The own-fund owncountry components are few in number, but explain much of what is happening in the cross section. Using this metric, approximately $2 / 3^{\text {rds }}$ of the persistence is attributable to own-fund owncountry persistence, i.e., the informed trader model. All the remaining cross effects contribute positively (this in contrast to that found by Froot and Tjornhom (2002) for developed countries). Of the remaining $1 / 3^{\text {rd }}$, approximately $1 / 2$ of that is attributable to cross-fund own-country 
persistence. The remaining part is attributable to own-fund, cross-country and cross-fund, crosscountry components, with the former being about twice the size of the latter.

Two plausible stories strike us as being consistent with these findings. The first is that there are meaningful implementation and decision-making lags across funds and across countries. Information may reach these funds at the same time, but those who act upon it do not do so simultaneously. There may be differences in the way investment decisions are made, or there may be other, fund-specific or country-specific aspects of the investment process that result in information being expressed in trades at different times.

Another plausible story is to explain the cross-country effects in emerging markets is that of contagion, but within and across funds. The predictable order flow in one country conditional on its past order flow and other countries' order flow suggest that selling (buying) may move predictably from one country to another. 


\section{References}

Brennan, M. and H. Cao, "International Portfolio Investment Flows," Journal of Finance 52, 1851-1880, 1997.

Choe, H., B.C. Kho, and R. Stulz, "Do Foreign Investors Destabilize Stock Markets? The Korean Experience in 1997," Journal of Financial Economics 54, 227-264, 1999.

Choe, H., B.C. Kho, and R. Stulz, "Do Domestic Investors Have More Valuable Information About Individual Stocks Than Foreign Investors?," NBER working paper no. W8073, 2001.

Chow, G., "Portfolio Selection Based on Return, Risk, and Relative Performance," Financial Analysts Journal, March-April, 54-60, 1995.

Cohen, R., P. Gompers, and T. Vuolteenaho, "Who Underreacts to Cashflow News? Evidence from Trading Between Individuals and Institutions," manuscript, Harvard University, 2001.

Froot, K., "Consistent Covariance Matrix Estimation With Cross-Sectional Dependence and Heteroskedasticity in Cross-Sectional Financial Data," Journal of Financial and Quantitative Analysis 24, 333-355, 1989.

Froot, K., P. O'Connell, and M. Seasholes, "The Portfolio Flows of International Investors," Journal of Financial Economics 59, 151-193, 2001.

Froot, K., and A. Perold, "New Trading Practices and Short-Run Market Efficiency," Journal of Futures Markets 15, 731-766, October 1995.

Froot, K., and T. Ramadorai, "The Information Content of International Portfolio Flows," NBER working paper no. 8472, September 2001.

Froot, K., D. Scharfstein and J. Stein, "Herd on the Street: Informational Inefficiencies in a Model with Short-Term Speculation," Journal of Finance, 47 (September 1992), 14611484.

Froot, K., and J. Tjornhom, "Decomposing the Persistence of International Equity Flows," NBER Working Paper no. 9079, July 2002.

Goetzmann, W., M. Massa, and G. Rouwenhorst, "Behavioral Factors in Mutual Fund Flows," Yale ICF working paper no. 00-14, 1999.

Grinblatt, M., and M. Keloharju, "The Investment Behavior and Performance of Various Investor-Types: A Study of Finland's Unique Data Set," Journal of Financial Economics $55,43-67,2000$.

Grinblatt, M., S. Titman, and R. Wermers, "Momentum Investment Strategies, Portfolio Performance, and Herding: A Study of Mutual Fund Behavior," American Economic Review 85, 1088-1105, 1995. 
Jegadeesh, N. and S. Titman, "Returns to Buying Winners and Selling Losers: Implications for Stock Market Efficiency," Journal of Finance 48, 65-91, 1993.

Kaminsky, G., R. Lyons, and S. Schmulker, "Managers, Investors, and Crises: Mutual Fund Strategies in Emerging Markets," World Bank, 2000.

Kim, W., and S.J. Wei, "Foreign Portfolio Investors Before and During a Crisis," Journal of International Economics 56, 77-96, 2000.

Kyle, A., "Continuous Auctions and Insider Trading,” Econometrica 53, 1315-1336, 1985.

Kyle, A., and W. Xoing, "Contagion as a Wealth Effect," Journal of Finance 55, 4, 1401-1443, 2001.

Lakonishok, J., A. Shleifer, and R. Vishny, "The Impact of Institutional Trading on Stock Prices," Journal of Financial Economics 32, 23-43, 1992.

Lo, A. and C. MacKinlay, "Stock Market Prices Do Not Follow Random Walks: Evidence From a Simple Specification Test," Review of Financial Studies 1, 41-66, 1988.

Nofsinger, J., and R. Sias, "Herding and Feedback Trading by Institutional and Individual Investors," Journal of Finance 54, 2263-2295, 1999.

Richards, A., "Big Fish in Small Ponds: the Momentum Investing and Price Impact of Foreign Investors in Asian Emerging Equity Markets," draft discussion paper, Reserve Bank of Australia, 2002.

Rouwenhorst, G., “International Momentum Strategies, ” Journal of Finance 53, 1998.

Seasholes, M., "Smart Foreign Traders in Emerging Earkets," University of California Berkeley, 2000.

Sias, R., "Price Pressure and the Role of Institutional Investors in Closed-End Funds," Journal of Financial Research 20, 211-229, 1997.

VanRoyen, A.S. and S. Page, "The Multiple Dimensions of Asset Allocation: Countries, Sectors, or Factors?," State Street Associates, 2002.

Wermers, R., "Mutual Fund Herding and the Impact on Stock Prices," Journal of Finance 54, 581-622, 1999.

Wermers, R., "Mutual Fund Performance: An Empirical Decomposition into Stock-Picking Talent, Style, Transaction Costs, and Expenses," Journal of Finance 55, 1655-1695. 
Figure 1: $\Gamma$, The Fund/Country Non-contemporaneous Covariance Matrix
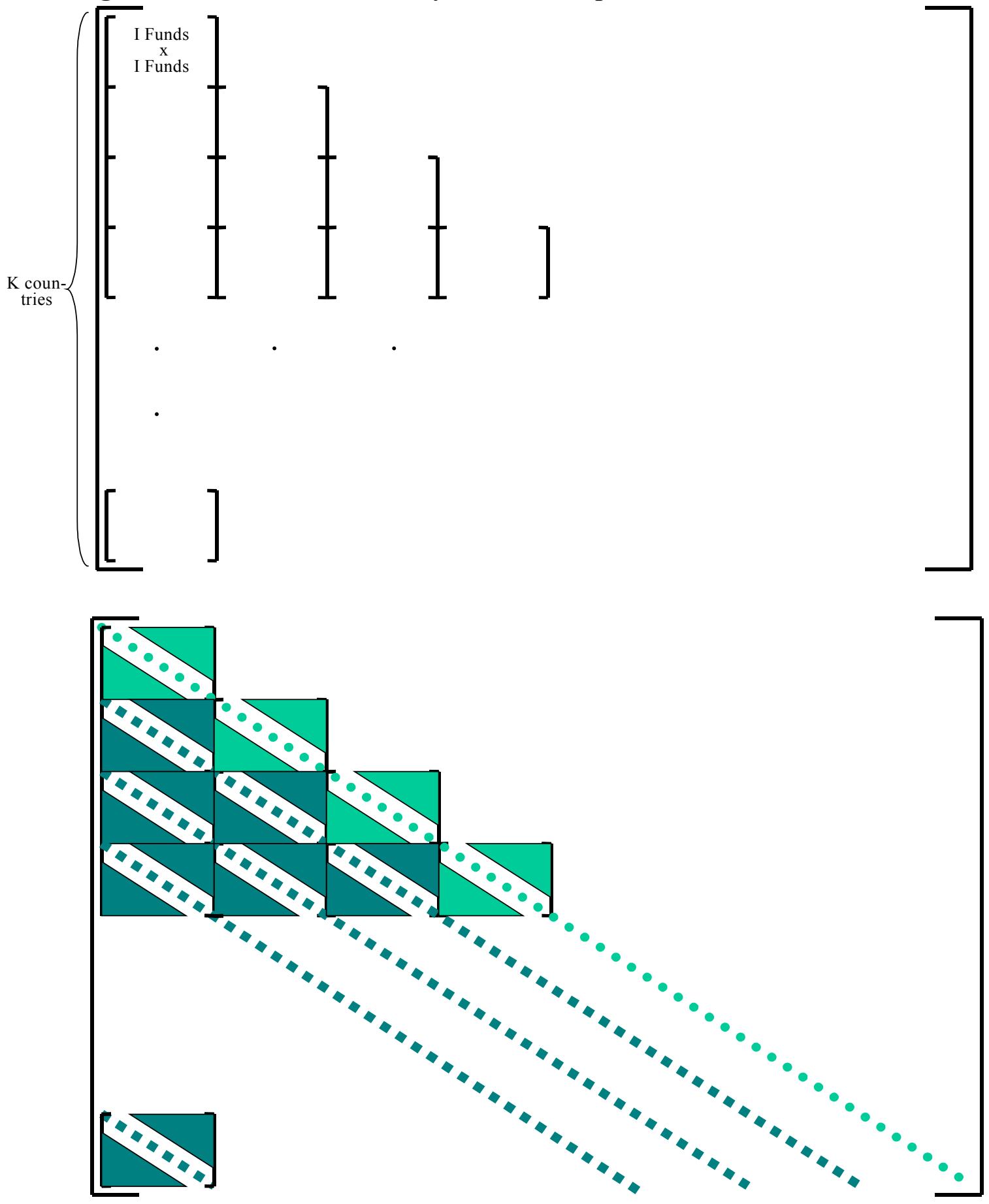

$\ldots$ Own-fund own-country covariance, $\alpha_{o}$

..... Own-fund cross-country covariance, $\alpha_{o c}$

Cross-fund own-country covariance, $\alpha_{\mathrm{co}}$

Cross-fund cross-country covariance, $\alpha_{\mathrm{cc}}$ 


\section{Figure 2: Trading by Date of Individual Funds}

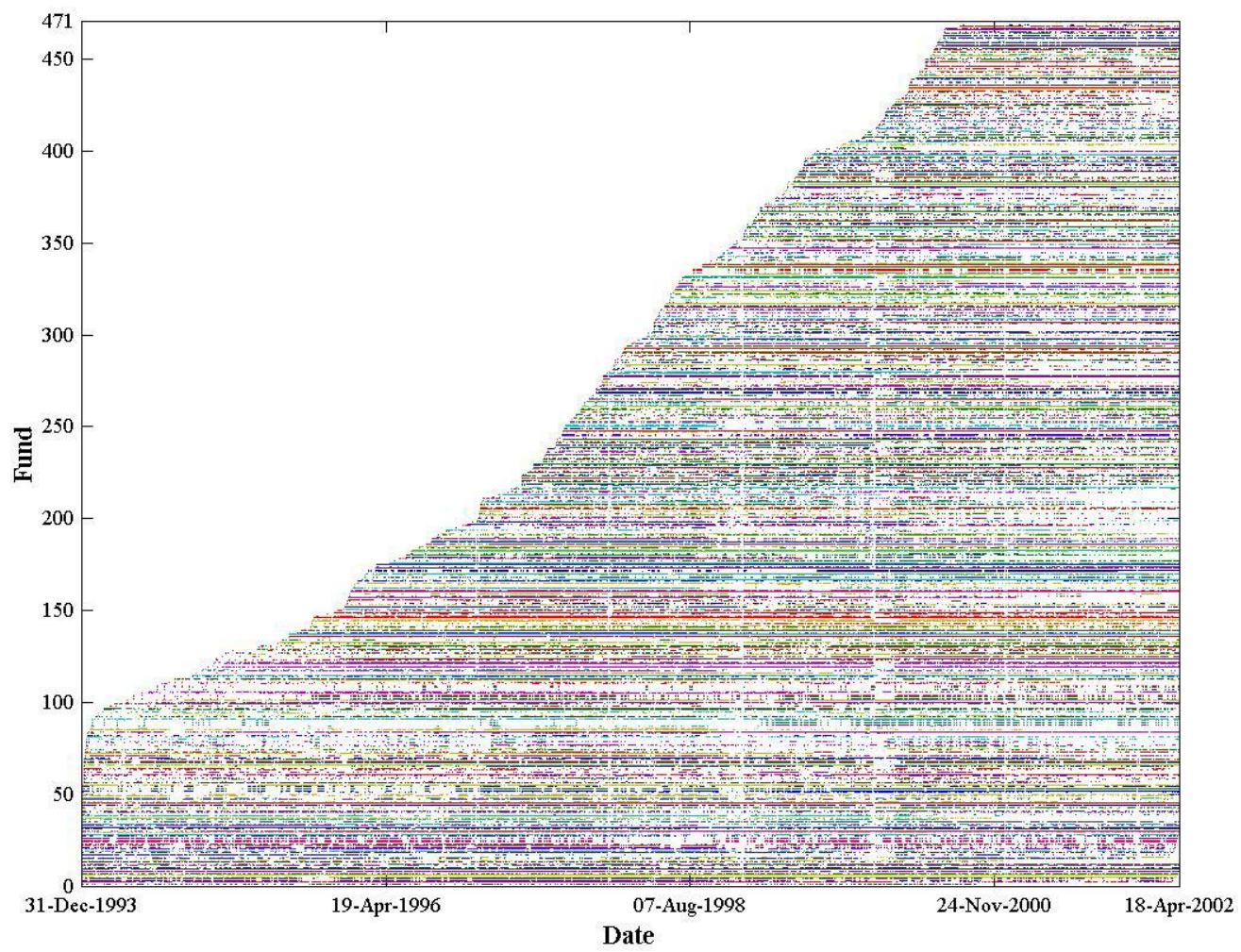


Figure 3: Number of Trades by Individual Funds for Each Country

(relative to individual fund total number of trades over all countries)
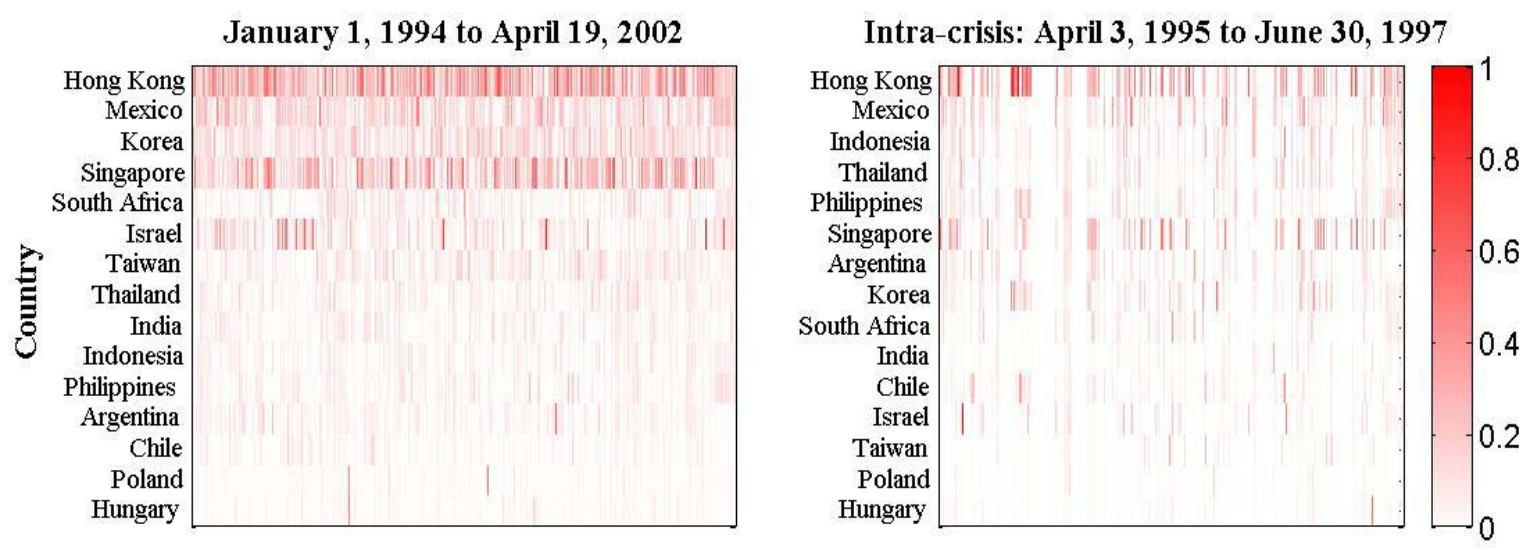

Crisis: July 1, 1997 to September 30, 1998

Post-crisis: October 1, 1998 to April 19, 2002
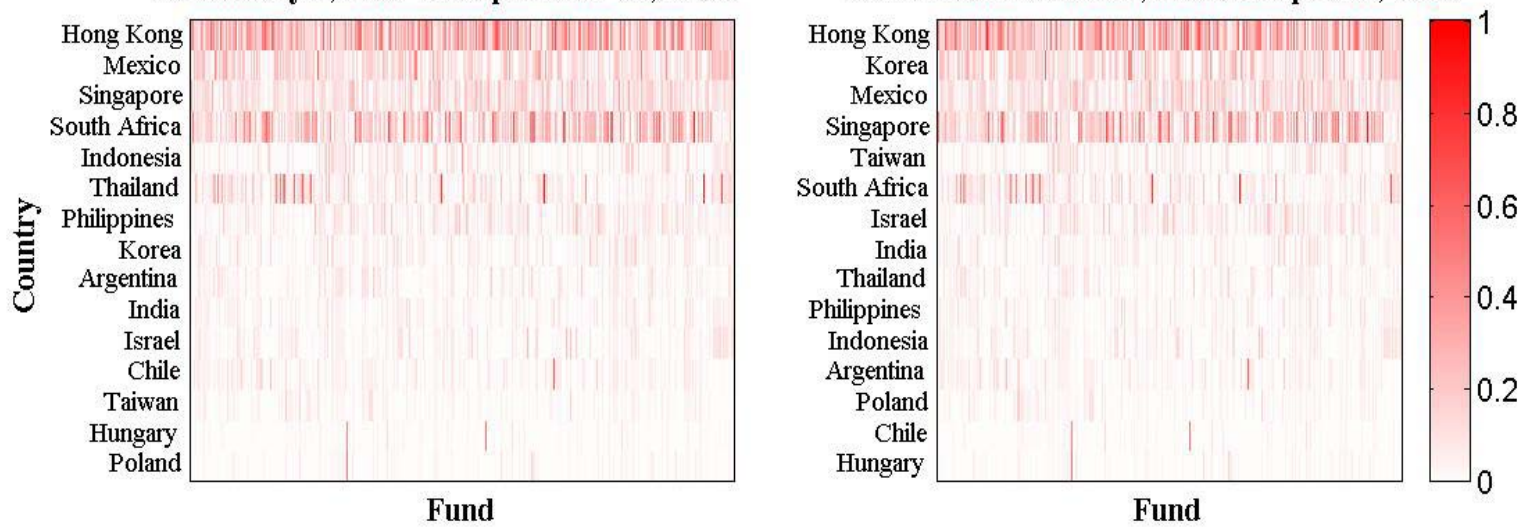
Figure 4: Volume of Net Flows by Individual Funds for Each Country (relative to individual fund total volume over all countries)

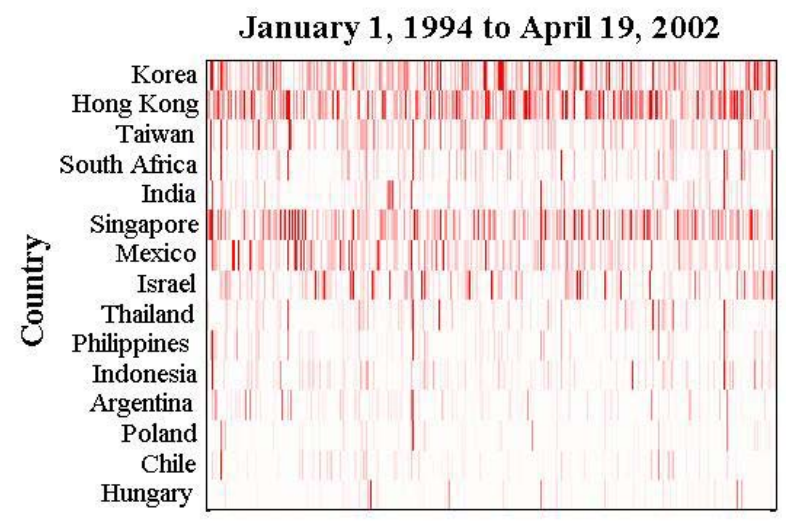

Crisis: July 1, 1997 to September 30, 1998

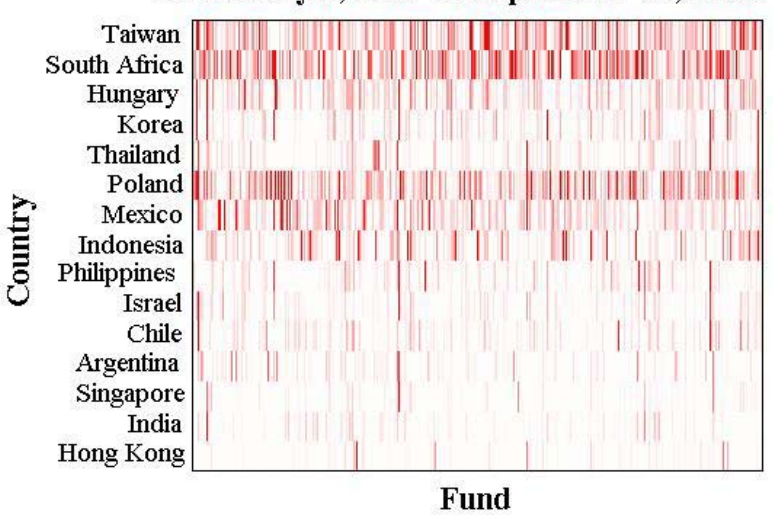

Intra-crisis: April 3, 1995 to June 30, 1997

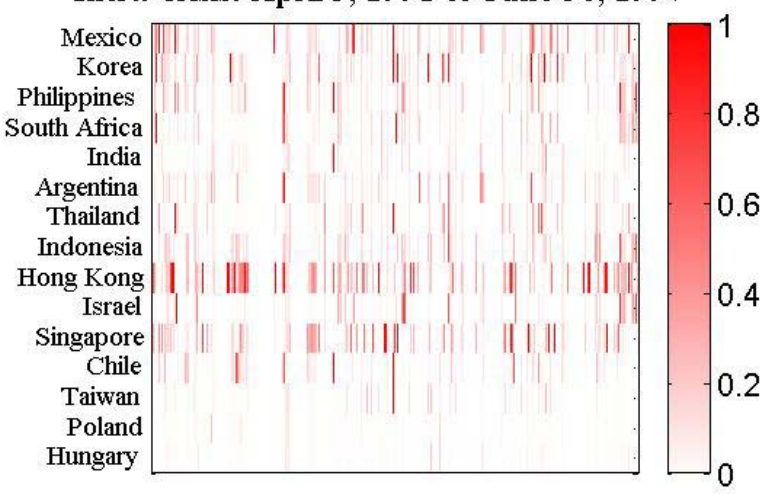

Post-crisis: October 1, 1998 to April 19, 2002

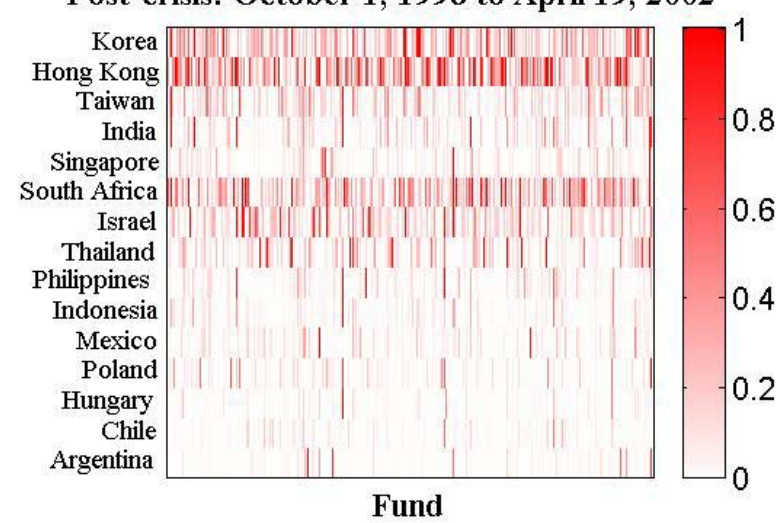


Figure 5: Weekly Correlation of Flows Across Countries

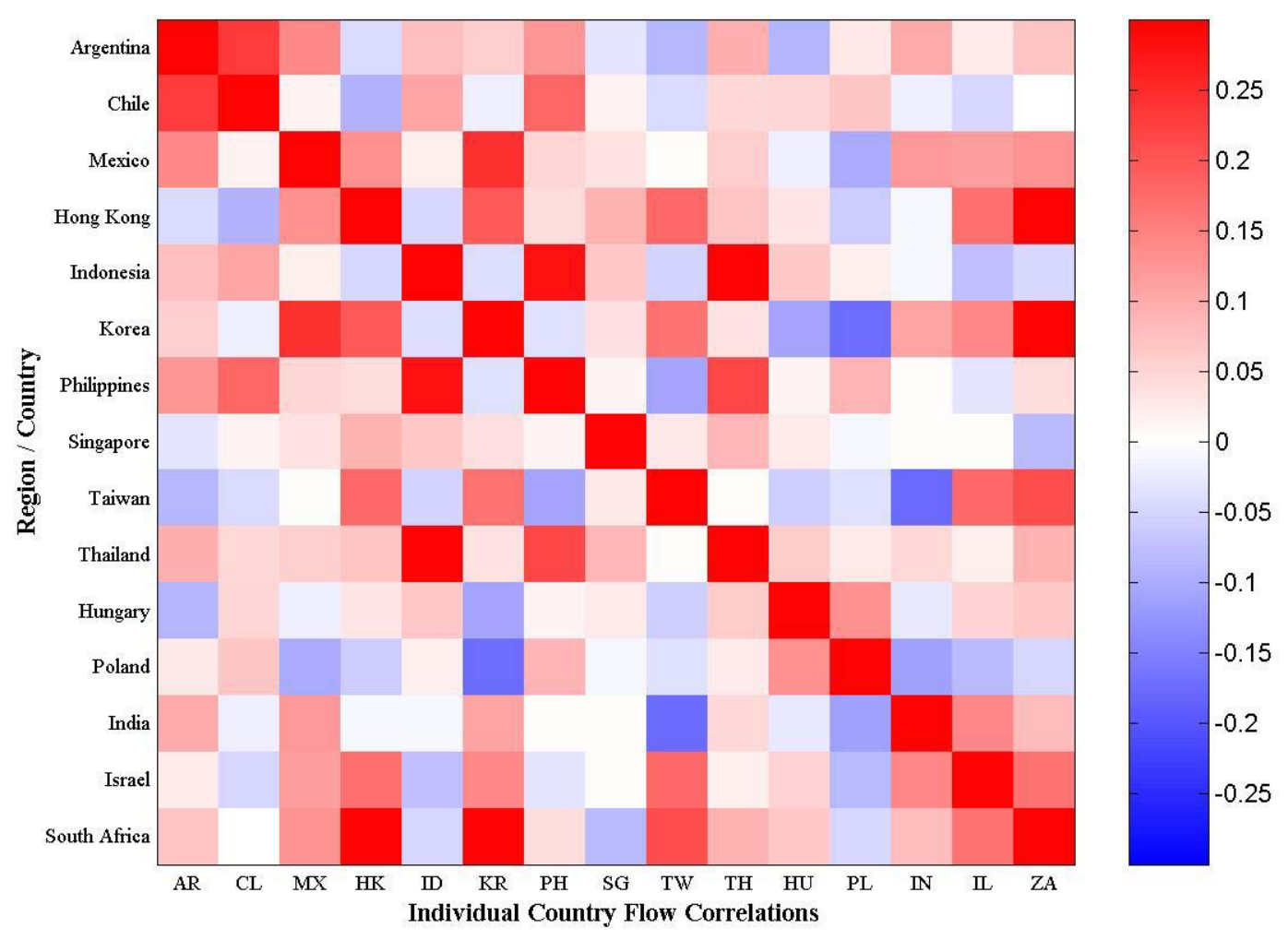


Figure 6: Weekly Correlations of Flows Across Regions

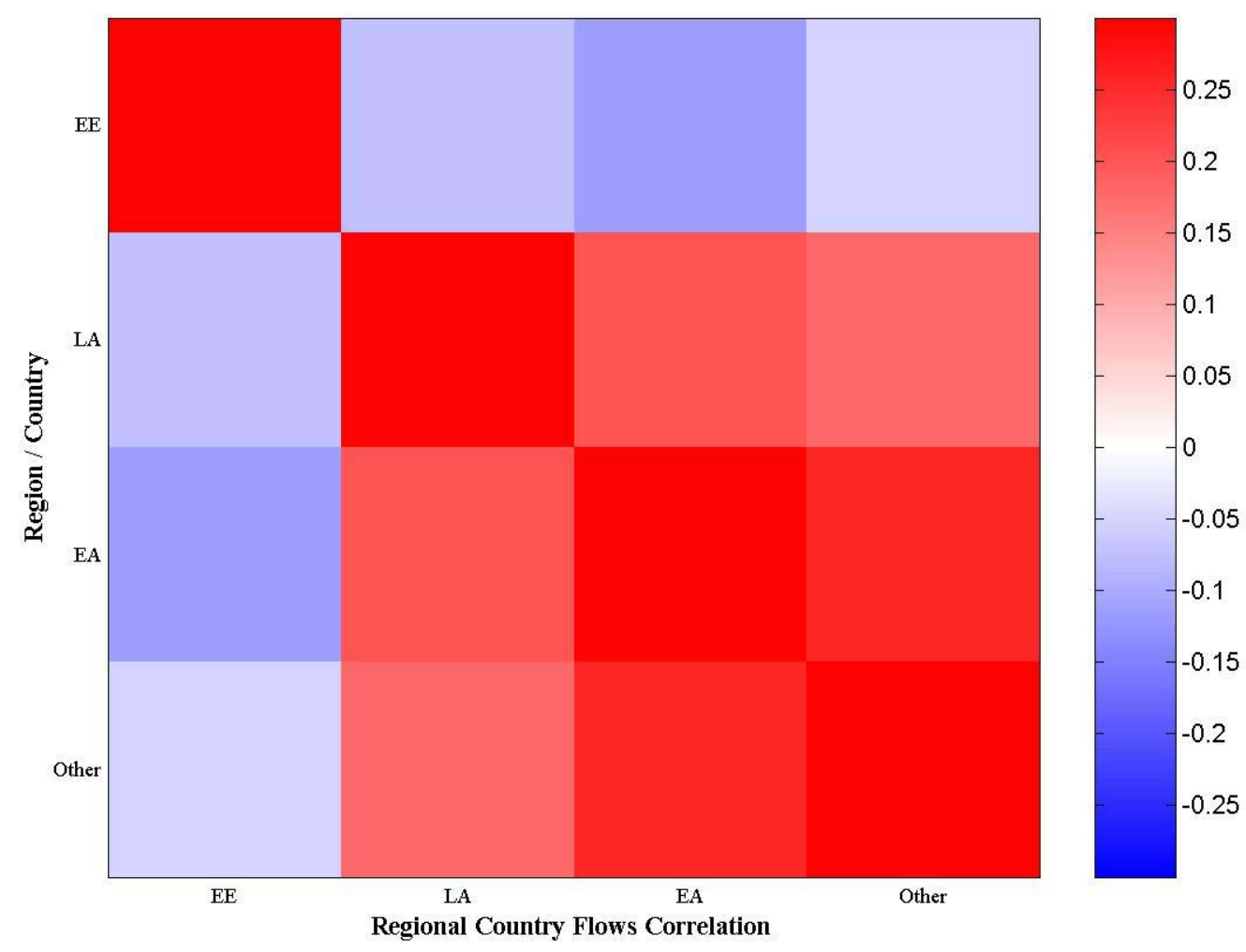

Regions include EE ("Emerging Europe" - Hungary, Poland), LA ("Latin America" - Argentina, Chile, Mexico), EA ("Emerging Asia" - Hong Kong, Indonesia, Korea, Philippines, Singapore, Taiwan, Thailand), Other ("Other Emerging" - India, Israel, South Africa). 


\section{Table 1.1 Descriptive Statistics for Net U.S. Dollar Flows}

The table provides the summary data on the net flows of institutional investors, across funds and countries. The flows cover 15 emerging markets. In the first column below we report for fund $\mathrm{i}$ and country $\mathrm{k}$ at time $\mathrm{t}, F_{i k t}$, the net U.S. dollar net flow. The second column sums the net dollar flows over all funds $\mathrm{j}$ not equal to $\mathrm{i}$ for a given country $\mathrm{k}$ at each time period. The third variable gives, for fund $\mathrm{i}$, the sum of all of its flows into countries other than k. Finally, the last term is the sum of flows over all country and fund pairs that do not include fund $\mathrm{i}$ and country $\mathrm{k}$. The summary data we report include the mean, $\mu$, the standard deviation, $\sigma$, and the first and second order autocorrelations, $\rho_{1}$ and $\rho_{2}$, stacking the data across $i$ and $\mathrm{k}$. The first and second autocorrelations are calculated by regressing the variable in question on two lags of itself for each $(\mathrm{i}, \mathrm{k})$ pair and then averaging across all active funds in country $\mathrm{k}$.

\begin{tabular}{rrrrc}
\hline & $F_{i, k, t}$ & $\sum_{j \neq i} F_{j, k, t-\tau}$ & $\sum_{l \neq k} F_{i, l, t-\tau}$ & $\sum_{j \neq i} \sum_{l \neq k} F_{j, l, t-\tau}$ \\
$\mu^{*}$ & 2.01 & 636.32 & 28.11 & $8,908.40$ \\
$\sigma^{*}$ & 299.35 & $9,523.90$ & $1,247.10$ & $40,545.00$ \\
$\boldsymbol{N}$ & $8,941,905$ & $8,941,905$ & $8,941,905$ & $8,941,905$ \\
$\rho_{1}$ & 0.1247 & 0.2255 & 0.1357 & 0.3566 \\
$\rho_{2}$ & 0.0388 & 0.1031 & 0.0516 & 0.1370 \\
\hline
\end{tabular}

* Note that the mean and standard deviations are in thousands of U.S. Dollars. 


\section{Table 1.2 Descriptive Statistics for Digital Signal}

The table provides the summary data on the sign or digital signal of net flows of institutional investors, across funds and countries where a net inflow is represented as a +1 , a net outflow as -1 and no flow is 0 . The flows cover 15 emerging markets. In the first column below we report for fund $\mathrm{i}$ and country $\mathrm{k}$ at time $\mathrm{t}, f_{i k t}$, the net U.S. Dollar flow signal for country k. The second column sums the net dollar flows signals over all funds $\mathrm{j}$ not equal to $\mathrm{i}$ for a given country $\mathrm{k}$ at each time period. The third variable gives, for fund $\mathrm{i}$, the sum of all of its flow signals into countries other than k. Finally, the last term is the sum of flow signals over all country and fund pairs that do not include fund $\mathrm{i}$ and country $\mathrm{k}$. The summary data we report include the mean, $\mu$, the standard deviation, $\sigma$, and the first and second order autocorrelations, $\rho_{1}$ and $\rho_{2}$, stacking the data across $\mathrm{i}$ and $\mathrm{k}$. The first and second autocorrelations are calculated by regressing the variable in question on two lags of itself for each $(\mathrm{i}, \mathrm{k})$ pair and then averaging across all active funds in country.

\begin{tabular}{lrrrr}
\hline & $f_{i, k, t}^{d}$ & $\sum_{j \neq i} f_{j, k, t}^{d}$ & $\sum_{l \neq k} f_{i, l, t}^{d}$ & $\sum_{j \neq i} \sum_{l \neq k} f_{j, l, t}^{d}$ \\
$\mu$ & 0.0025 & 0.6214 & 0.0356 & 8.6999 \\
$\sigma$ & 0.2238 & 9.1181 & 0.9847 & 39.2878 \\
$\rho_{1}$ & 0.2921 & 0.3857 & 0.3275 & 0.4519 \\
$\rho_{2}$ & 0.0955 & 0.1552 & 0.1155 & 0.1258 \\
\hline
\end{tabular}

\section{Table 1.3 Descriptive Statistics for the Buy-Sell Ratio}

The table provides the summary data on the buy-sell ratio, the ratio of the number of buy transactions minus the number of sell transactions as a percentage of total buy and sell transactions, of net flows of institutional investors, across funds and countries. The flows cover 15 emerging markets. In the first column below we report for fund $\mathrm{i}$ and country $\mathrm{k}$ at time $\mathrm{t}, f^{c}{ }_{i k t}$, the buy-sell ratio for country $\mathrm{k}$. The second column sums the buy-sell ratio over all funds $\mathrm{j}$ not equal to $\mathrm{i}$ for a given country $\mathrm{k}$ at each time period. The third variable gives, for fund $i$, the sum of all of its buy-sell ratios into countries other than k. Finally, the last term is the sum of buy-sell ratios over all country and fund pairs that do not include fund i and country $\mathrm{k}$. The summary data we report include the mean, $\mu$, the standard deviation, $\sigma$, and the first and second order autocorrelations, $\rho_{1}$ and $\rho_{2}$, stacking the data across $i$ and $\mathrm{k}$. The first and second autocorrelations are calculated by regressing the variable in question on two lags of itself for each $(\mathrm{i}, \mathrm{k})$ pair and then averaging across all active funds in country $\mathrm{k}$.

\begin{tabular}{llllr}
\hline & $f_{i, k, t}^{c}$ & $\sum_{j \neq i} f_{j, k, t}^{c}$ & $\sum_{l \neq k} f_{i, l, t}^{c}$ & $\sum_{j \neq i} \sum_{l \neq k} f_{j, l, t}^{c}$ \\
$\mu$ & & & & \\
$\sigma$ & 0.0022 & 0.5012 & 0.0307 & 7.0166 \\
$\rho_{1}$ & 0.2140 & 8.8425 & 0.9508 & 38.0787 \\
$\rho_{2}$ & 0.3071 & 0.4023 & 0.3457 & 0.4707 \\
\hline
\end{tabular}




\section{Table 2.1 Covariance Decomposition}

This table reports the decomposition of total flow autocorrelation into four components: own lag, lagged cross-fund own-country signals, lagged own-fund cross-country signals and cross-fund cross-country signals for. The decomposition is based on the equation.

$$
\alpha(\tau)=\left(\alpha_{o o}(\tau)+\alpha_{o c}(\tau)+\alpha_{c o}(\tau)+\alpha_{c c}(\tau)\right)
$$

We use digital signals of underlying net flows for this decomposition. The results are obtained by regressing a single lag of each of the four component variables on, $f^{d}{ }_{i k t}$, the net U.S. Dollar flow signal for country $\mathrm{k}$. We also report the composition in terms of percentages.

\begin{tabular}{|c|c|c|c|c|c|}
\hline & & $\alpha_{o o}(\tau)$ & $\alpha_{c o}(\tau)$ & $\alpha_{o c}(\tau)$ & $\alpha_{c c}(\tau)$ \\
\hline $1^{\text {st }}$ order & 1036 & 98.64 & 507.81 & 67.52 & 426.04 \\
\hline Percentage of Total & & $3.72 \%$ & $19.13 \%$ & $2.54 \%$ & $16.05 \%$ \\
\hline $2^{\text {nd }}$ order & 861 & 71.04 & 381.05 & 48.18 & 343.65 \\
\hline Percentage of Total & & $2.68 \%$ & $14.35 \%$ & $1.81 \%$ & $12.94 \%$ \\
\hline $3^{\text {rd }}$ order & 758 & 56.33 & 312.75 & 42.55 & 299.45 \\
\hline Percentage of Total & & $2.12 \%$ & $11.78 \%$ & $1.60 \%$ & $11.28 \%$ \\
\hline Total & 2655 & & & & \\
\hline
\end{tabular}




\section{Table 2.2 Autoregressive Behavior of Digital Equity Flow Signals}

The table reports the first, second and third order autoregressive coefficient for the digital signals where a net inflow is represented as a +1 , a net outflow as -1 and no flow is 0 . Each column represents the results for the autoregression. The first column reports the results for the sum of total signals across all 15 emerging countries and the 471 funds in our sample. Columns 2 to 5 give the results for each of the four digital variables discussed in Table 1.2. The equation being estimated in all cases is the following.

$$
f^{d}=c+a(L) f^{d}+\varepsilon_{t}
$$

The subscripts on the autoregressive coefficients indicate the flow variable used in the autoregression; $\alpha_{\mathrm{oo}}$ is the coefficient for the regression of own fund, own country digital signals, $\alpha_{\mathrm{co}}$ is the coefficient for cross fund-own country signals, $\alpha_{o c}$ is for own fund-cross country signals, and $\alpha_{c c}$ is for cross fund-cross country signals. Standard errors are reported in parentheses.

\begin{tabular}{|c|c|c|c|c|c|}
\hline & $f_{t}$ & $a_{o o}(L)$ & $a_{c o}(L)$ & $a_{o c}(l)$ & $a_{c c}(L)$ \\
\hline \multirow[t]{2}{*}{$1^{\text {st }}$ order } & 0.3466 & 0.3137 & 0.3284 & 0.1553 & 0.1771 \\
\hline & $(0.0047)$ & $(0.0003)$ & $(0.0031)$ & $(0.0012)$ & $(0.0105)$ \\
\hline \multirow[t]{2}{*}{$2^{\text {nd }}$ order } & 0.0733 & 0.1236 & 0.1069 & 0.0418 & 0.0605 \\
\hline & $(0.0049)$ & $(0.0003)$ & $(0.0034)$ & $(0.0013)$ & $(0.0115)$ \\
\hline \multirow[t]{2}{*}{$3^{\text {rd }}$ order } & 0.1236 & 0.0850 & 0.0791 & 0.0489 & 0.0578 \\
\hline & $(0.0047)$ & $(0.0003)$ & $(0.0031)$ & $(0.0012)$ & $(0.0105)$ \\
\hline$R^{2}$ & 0.2927 & 0.1737 & 0.0030 & 0.0041 & 0.0002 \\
\hline$S E$ & 14.8410 & 0.2030 & 0.2229 & 0.2228 & 0.2233 \\
\hline$N$ & 45,465 & $8,941,905$ & $8,941,905$ & $8,941,905$ & $8,941,905$ \\
\hline
\end{tabular}




\section{Table 3 Persistence of Institutional Investor's Flows}

This table shows the results of a regression of own-fund own-country digital signals from underlying flow data on its own lags, lagged cross-fund own-country signals, lagged own-fund cross-country signals and cross-fund cross-country signals. The equation estimated is the following.

$$
f_{i, k, t}=c+a_{o o}(L) f_{i, k, t-1}+a_{c o}(L) \sum_{j \neq i} f_{j, k, t-1}+a_{o c}(L) \sum_{l \neq k} f_{i, l, t-1}+a_{c c}(L) \sum_{j \neq i} \sum_{l \neq k} f_{j, l, t-1}+\varepsilon_{i, k, t}
$$

These results are for the set of 15 different emerging country equity markets in our sample. Results are reported for both the daily and weekly frequency. Standard errors are reported in parentheses.

Daily Data

$\mathbf{1}^{\text {st }}$ order

$2^{\text {nd }}$ order

$3^{\text {rd }}$ order $a_{o o}(L)$

0.3112

(0.0003)

0.1231

(0.0003)

0.0844

(0.0003)

$R^{2}$

0.1742

$S E$

0.2029

N $8,941,905$

\section{Weekly Data}

$1^{\text {st }}$ order

0.3656

(0.0008)

$2^{\text {nd }}$ order

0.0534

(0.0008)

$3^{\text {rd }}$ order

0.0532

(0.0008)

$\begin{array}{rr}\boldsymbol{R}^{2} & 0.1698 \\ \boldsymbol{S E} & 0.6711 \\ \boldsymbol{N} & 1,785,660\end{array}$

$a_{c o}(L) \quad a_{o c}(l) \quad a_{c c}(L)$

$\begin{array}{lll}0.0855 & 0.0653 & 0.0195\end{array}$

$\begin{array}{lll}(0.0029) & (0.0011) & (0.0096)\end{array}$

$\begin{array}{lll}0.0028 & -0.0128 & 0.0046\end{array}$

$\begin{array}{lll}(0.0031) & (0.0012) & (0.0105)\end{array}$

$\begin{array}{lll}0.0063 & 0.0177 & -0.0041\end{array}$

$\begin{array}{lll}(0.0029) & (0.0011) & (0.0096)\end{array}$ 


\section{Table 4 Persistence of Institutional Investor's Flows including Returns}

This table shows the results of a regression of own-fund own-country digital signals from underlying net flows of institutional investors on its own lags, cross-fund own-country signals, own-fund cross-country signals, cross-fund cross-country signals, own-country returns and returns in the U.S. market as the proxy for cross-country returns. The equation estimated is the following.

$f_{i, k, t}=c+a_{o o}(L) f_{i, k, t-1}+a_{c o}(L) \sum_{j \neq i} f_{j, k, t-1}+a_{o c}(L) \sum_{l \neq k} f_{i, l, t-1}+a_{c c}(L) \sum_{j \neq i} \sum_{l \neq k} f_{j, l, t-1}+b_{o}(L) r_{i, t-1}+b_{c}(L) r_{j, t-1}+\varepsilon_{i, k, t}$

These results are for the set of 15 emerging country equity markets in our sample. Results are reported for both the daily and weekly frequency. Standard errors are reported in parentheses.

\begin{tabular}{|c|c|c|c|c|c|c|}
\hline Daily Data & $a_{o o}(L)$ & $a_{c o}(L)$ & $a_{o c}(L)$ & $a_{c c}(L)$ & $b_{o}(L)$ & $b_{c}(L)$ \\
\hline $1^{\text {st }}$ order & $\begin{array}{r}0.3112 \\
(0.0003)\end{array}$ & $\begin{array}{r}0.0845 \\
(0.0029)\end{array}$ & $\begin{array}{r}0.0652 \\
(0.0011)\end{array}$ & $\begin{array}{r}0.0143 \\
(0.0097)\end{array}$ & $\begin{array}{r}0.0520 \\
(0.0032)\end{array}$ & $\begin{array}{r}0.0533 \\
(0.0060)\end{array}$ \\
\hline $2^{\text {nd }}$ order & $\begin{array}{r}0.1231 \\
(0.0003)\end{array}$ & $\begin{array}{r}0.0019 \\
(0.0031)\end{array}$ & $\begin{array}{l}-0.0128 \\
(0.0012)\end{array}$ & $\begin{array}{r}0.0021 \\
(0.0106)\end{array}$ & $\begin{array}{r}0.0205 \\
(0.0032)\end{array}$ & $\begin{array}{r}0.0104 \\
(0.0061)\end{array}$ \\
\hline $3^{\text {rd }}$ order & $\begin{array}{r}0.0844 \\
(0.0003)\end{array}$ & $\begin{array}{r}0.0066 \\
(0.0029)\end{array}$ & $\begin{array}{r}0.0117 \\
(0.0011)\end{array}$ & $\begin{array}{r}-0.0030 \\
(0.0096)\end{array}$ & $\begin{array}{r}0.0055 \\
(0.0031)\end{array}$ & $\begin{array}{l}-0.0044 \\
(0.0061)\end{array}$ \\
\hline $\begin{array}{r}R^{2} \\
S E \\
N\end{array}$ & $\begin{array}{r}0.1742 \\
0.2029 \\
8,941,905\end{array}$ & & & & & \\
\hline Weekly Data & $a_{o o}(L)$ & $a_{c o}(L)$ & $a_{o c}(L)$ & $a_{c c}(L)$ & $b_{o}(L)$ & $b_{c}(L)$ \\
\hline $1^{\text {st }}$ order & $\begin{array}{r}0.3656 \\
(0.0008)\end{array}$ & $\begin{array}{c}0.0587 \\
(0.0060)\end{array}$ & $\begin{array}{r}0.0485 \\
(0.0024)\end{array}$ & $\begin{array}{l}-0.0134 \\
(0.0196)\end{array}$ & $\begin{array}{r}0.1086 \\
(0.0101)\end{array}$ & $\begin{array}{r}0.0809 \\
(0.0217)\end{array}$ \\
\hline $2^{\text {nd }}$ order & $\begin{array}{r}0.0534 \\
(0.0008)\end{array}$ & $\begin{array}{r}0.0271 \\
(0.0065)\end{array}$ & $\begin{array}{r}0.0004 \\
(0.0026)\end{array}$ & $\begin{array}{r}0.0364 \\
(0.0212)\end{array}$ & $\begin{array}{l}-0.0056 \\
(0.0101)\end{array}$ & $\begin{array}{c}0.0454 \\
(0.0220)\end{array}$ \\
\hline $3^{\text {rd }}$ order & $\begin{array}{r}0.0532 \\
(0.0008)\end{array}$ & $\begin{array}{r}0.0331 \\
(0.0060)\end{array}$ & $\begin{array}{r}0.0173 \\
(0.0024)\end{array}$ & $\begin{array}{r}0.0269 \\
(0.0192)\end{array}$ & $\begin{array}{l}-0.0144 \\
(0.0101)\end{array}$ & $\begin{array}{r}0.0438 \\
(0.0218)\end{array}$ \\
\hline $\begin{array}{r}R^{2} \\
S E \\
N\end{array}$ & $\begin{array}{r}0.1699 \\
0.6710 \\
1,785,660\end{array}$ & & & & & \\
\hline
\end{tabular}




\section{Table 5 Persistence with Country Specific Coefficients}

This table shows the results of a regression of weekly own-fund own-country digital signals from underlying net flows of institutional investors on its own lags, cross-fund own-country signals, own-fund cross-country signals, cross-fund cross-country signals, own-country returns and returns in the U.S. market as the proxy for cross-country returns. This specification includes separate own-fund own-country autoregressive coefficients for each market, $k$. The equation estimated is the following.

$$
\begin{aligned}
f_{i, k, t}= & c_{i, k}+a_{o o ; k}(L) f_{i, k, t-1}+a_{c o}(L) \sum_{j \neq i} f_{j, k, t-1}+a_{o c}(L) \sum_{l \neq k} f_{i, l, t-1}+a_{c c}(L) \sum_{j \neq i} \sum_{l \neq k} f_{j, l, t-1} \\
& +b_{o}(L) r_{i, t-1}+b_{c}(L) r_{j, t-1}+\varepsilon_{i, k, t}
\end{aligned}
$$

These results in the upper panel are for the 15 emerging country equity markets in our sample. Standard errors are reported in parentheses.

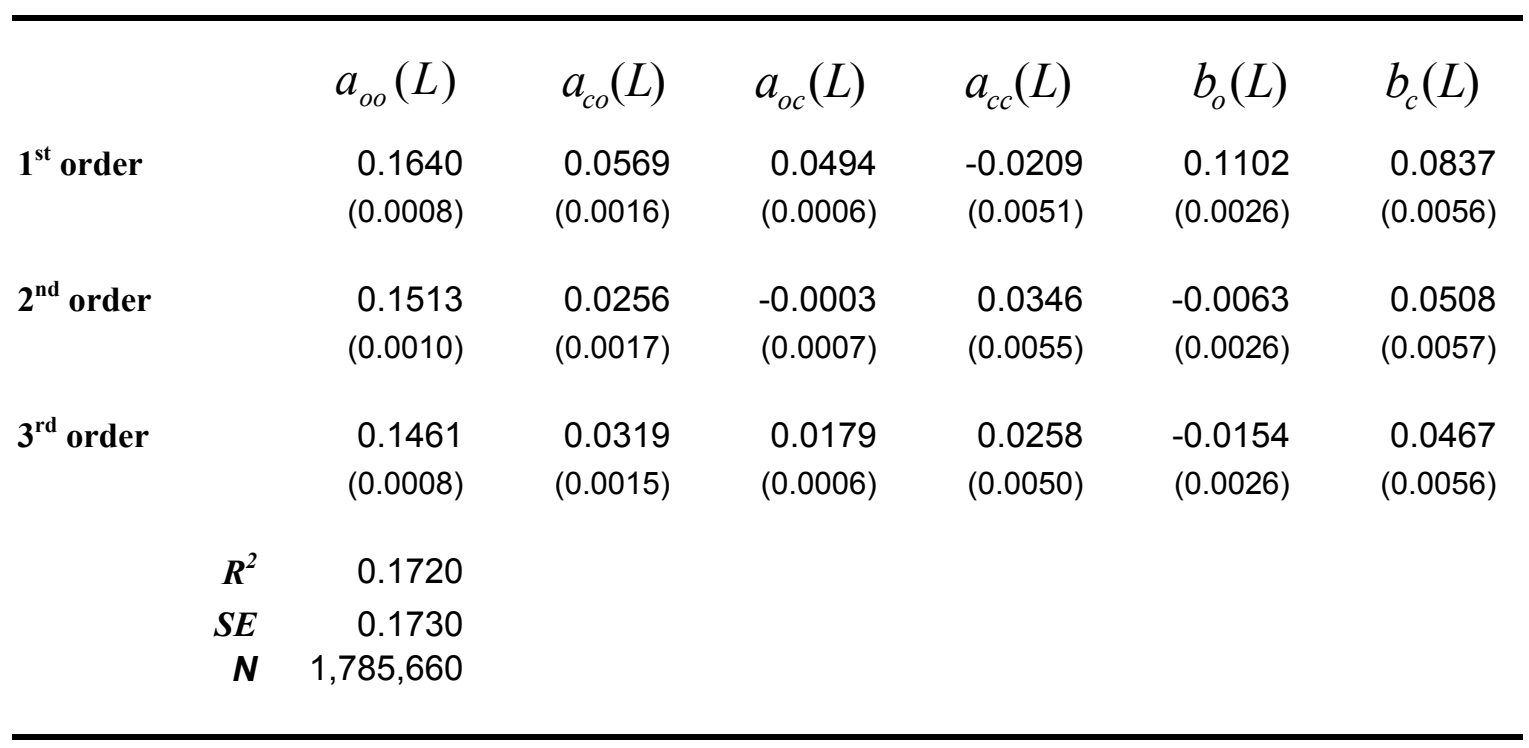

